\title{
Hazardous Material Reduction Initiative
}

\author{
D. H. Nichols
}

Date Published

February 1995

\section{DISCLAIMER}

This report was prepared as an account of work sponsored by an agency of the United States Government. Neither the United States Government nor any agency thereof, nor any of their employees, makes any warranty, express or implied, or assumes any legal liability or responsibility for the accuracy, completeness, or usefuiness of any information, apparatus, product, or process disclosed, or represents that its use would not infringe privately owned rights. Reference herein to any specific commercial product, process, or service by trade name, trademark, manufacturer, or otherwise does not necessarily constitute or imply its endorsement, recommendation, or favoring by the United States Government or any agency thereof. The views and opinions of authors expressed herein do not necessarily state or reflect these of the United States Government or any agency thereof.

Prepared for the U.S. Department of Energy Office of Environmental Restoration and Waste Management

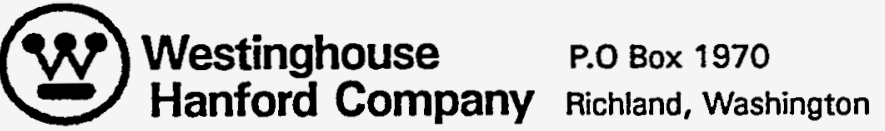

Hanford Operations and Engineering Contractor for the

U.S. Department of Energy under Contract DE-ACO6-87RL10930

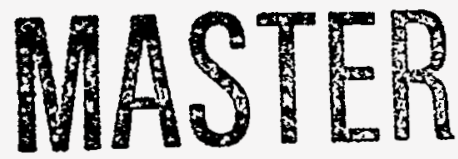

Approved for Public Release

DISTRIRUTION OF THIS DOCUMENT IS UNLIMTEE 


\section{DISCLAIMER}

Portions of this document may be illegible in electronic image products. Images are produced from the best available original document. 


\section{RELEASE AUTHORIZATION}

Document Number: WHC-MR-0484

Document Title: Hazardous Waste Reduction Initiative

Release Date: $\quad 2 / 23 / 95$

This document was reviewed following the procedures described in WHC-CM-3-14 and is:

APPROVED FOR PUBLIC RELEASE

WHC Information Release Administration Specialist:

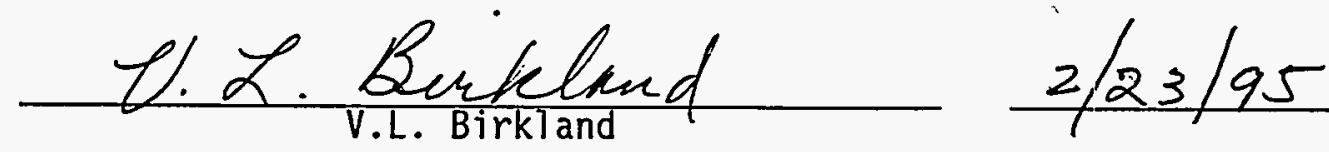


WHC-MR-0484

\section{EXECUTIVE SUMMARY}

The Hazardous Material Reduction Initiative (HMRI) explores using the review of purchase requisitions to reduce both the use of hazardous materials and the generation of regulated and nonregulated wastes.

Based on an 11-month program implemented at the Hanford Site, hazardous material use and waste generation was effectively reduced by using a centralized procurement control program known as HMRI. As expected, several changes to the original proposal were needed during the development/testing phase of the program to accommodate changing and actual conditions found at the Hanford Site. Additional refinements are planned and will be incorporated as new sources of information become available. This report includes all steps involved in the development of HMRI to aid others in implementing a similar program.

The current method requires a central receiving point within the Procurement Organization to review all purchase requisitions for potentially Occupational Safety and Health Administration (OSHA) hazardous products. Those requisitions (approximate $74 \%$ to $6 \%$ of the total) are then forwarded to Pollution Prevention personnel for evaluation under HMRI. The first step is to determine if the requested item can be filled by existing or surplus material. The requisitions that cannot filled by existing or surplus material are then sorted into two groups based on applicability to the HMRI project. For example, laboratory requests for analytical reagents or standards are excluded and the purchase requisitions are returned to Procurement for normal processing because, although regulated, there is little opportunity for source reduction due to the strict protocols followed. Each item is then checked to determine if it is regulated or not. Regulated items are prioritized based on hazardous contents, quantity requested, and end use. Copies of these requisitions are made and the originals are returned to Procurement within 1-hr. Since changes to the requisition can be made at later stages during procurement, the HMRI fulfills one of its original premises in that it does not slow the procurement process.

For the HMRI program to work effectively, field personnel are needed to contact manufacturers and distributors, obtain product samples, and provide the alternative product testing and evaluation. Product information collected from the field on product testing is then entered into a substitution listing for future reference.

During the first 11-month period, 660 product requests were reviewed. Substitutions were identified for products containing Class I ozone-depleting substances representing an estimated 2.5 metric tons annual usage, regulated paint usage was reduced 660 liters, and more than 10 metric tons of excess material was used to fill purchase requisitions. 
WHC-MR-0484

This page intentionally left blank. 


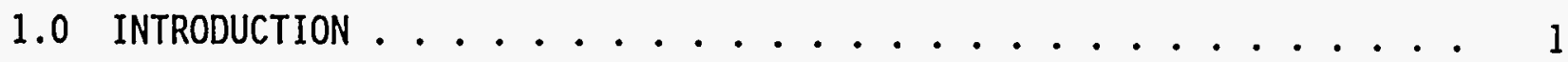

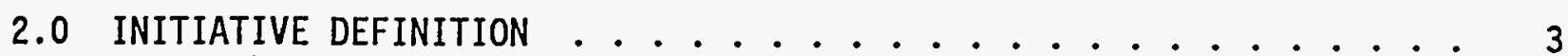

2.1 GOALS . . . . . . . . . . . . . . . . . 3

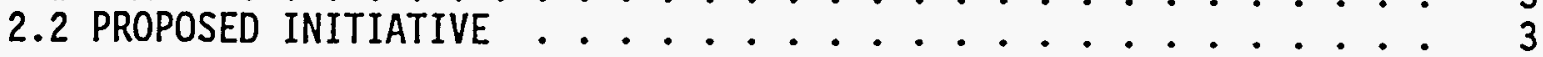

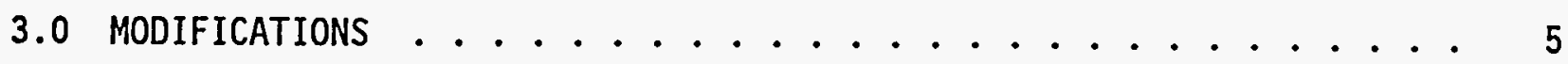

4.0 IMPLEMENTATION (WORKING MODEL) ............. 7

4.1 TOOLS

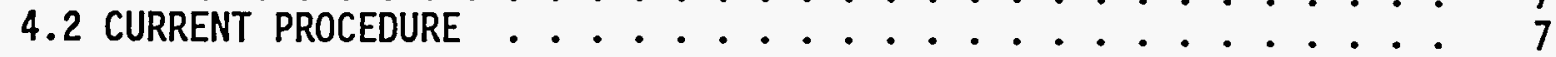

5.0 PROBLEMS AND PLANNED IMPROVEMENTS ................ 11

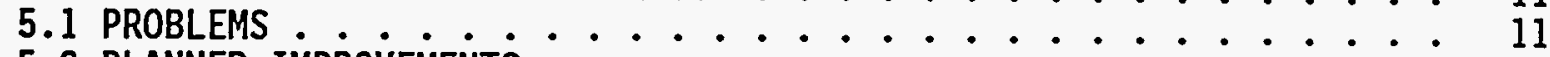

5.2 PLANNED IMPROVEMENTS $\ldots \ldots \ldots$

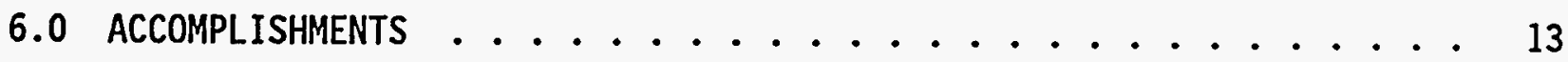

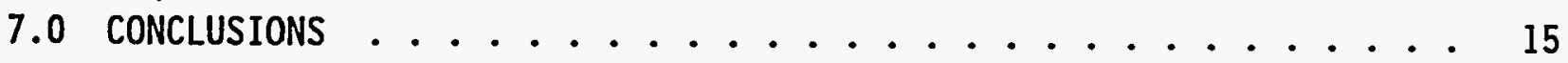

\section{LIST OF FIGURES}

1. Proposed Purchase Requisition Flow Using the Hazardous

Material Reduction Initiative ............. 4

2. Final Purchase Requisition Flow Using the Hazardous

Material Reduction Initiative .............. 9

3. Hazardous Material Reduction Initiative Detail ......... 10

\section{LIST OF TABLES}

1. Cumulative Requisitions Disposition since HMRI Implementation . . . 14 
WHC-MR-0484

This page intentionally left blank. 


\subsection{INTRODUCTION}

The Hazardous Material Reduction Initiative (HMRI) is funded by the U.S. Department of Energy-Headquarters (DOE-HQ) EM-334 Waste Minimization Division. The initiative uses carryover funds from the Packaging Reduction Project. This document provides the final report on the HMRI task.

The HMRI initiative has two purposes: (1) to reduce the amount of hazardous materials being brought onsite by offering less hazardous or nonhazardous product alternatives and (2) to provide a vehicle by which employees may become aware of the waste hazards of the materials with which they are working through participation in identifying and testing alternative products. Often, reducing the amount of hazardous materials will mean using a less hazardous substitute rather than using less of a current product.

One way to improve worker safety and minimize the amount of hazardous waste produced is to reduce the amount and toxicity of hazardous material purchased. This requires that all purchase requisitions for chemical products be evaluated. In addition, the products carried in store stocks must be controlled to ensure that the least hazardous products that will still do the job are the only ones carried.

At the Hestinghouse Hanford Company (WHC) there are several routes by which products containing hazardous substances enter the work place. Most often the products are obtained through traditional routes (e.g., through requisitions issued by the end user or as stock items from Central Stores or Systems Contracts). However, a small percentage of materials may also be left by off-site contractors or even brought from home.

Regardless of how these products enter the work place, they pose problems for worker safety in ensuring that current material safety data sheets are available and in properly identifying and disposing of the hazardous waste generated from the use of these products. In 1991, WHC made a proposal to unite segments of Procurement, Industrial Safety, and Pollution Prevention in a single program to ensure that (1) all products obtained through purchase requisitions were reviewed, (2) hazardous materials were identified, (3) current material safety data sheets were obtained, and (4) less hazardous alternatives were sought. This program was started in November 1993.

This report summarizes the Pollution Prevention aspect of that program and pertinent elements provided by Industrial Safety and Procurement through September 1994. 
WHC-MR-0484

This page intentionally left blank. 


\subsection{INITIATIVE DEFINITION}

\subsection{GOALS}

The following goals were set for the HMRI:

- Develop a product substitution list prior to implementing the initiative

- Reduce hazardous material procurement resulting in regulated waste by $25 \%$

- Provide a program that does not delay the procurement system.

\subsection{PROPOSED INITIATIVE}

In order for the HMRI to succeed, several WHC groups were required to coordinate their efforts. The Procurement Organization provided a single individual at one location to review and identify potentially hazardous products. The Pollution Prevention Organization coordinated the maintenance of a product substitution list identifying potential vendors and manufacturers for alternative products, directing applicable purchase requisitions to the Recycling Group, and alerting requestors to the need to seek alternative products. The HMRI involvement at this point requires less than one hour and does not significantly interrupt the normal flow of the requisition. The Site Services Organization reviewed material safety data sheets to determine U.S. Environmental Protection Agency (EPA) and Washington State defined waste codes associated with both currently used products and proposed substitutes. Waste codes were identified for old or unused product, used product, empty containers, and materials contaminated with $10 \%$ or more product resulting from application or cleanup activities. Industrial Safety identified Occupation Safety and Health Administration (OSHA) hazardous products, obtained and filed copies of material safety data sheets, and entered products and their constituents into the site hazardous material inventory database (HMID2). A product code is assigned by the buyer after the purchase requisition reaches their station. Facilities using these products entered both inventory quantities and their locations into HMID2. Figure 1 shows the proposed purchase requisition flow and actions upon implementing the HMRI. 
Figure 1. Proposed Purchase Requisition Flow Using the Hazardous Material Reduction Initiative.

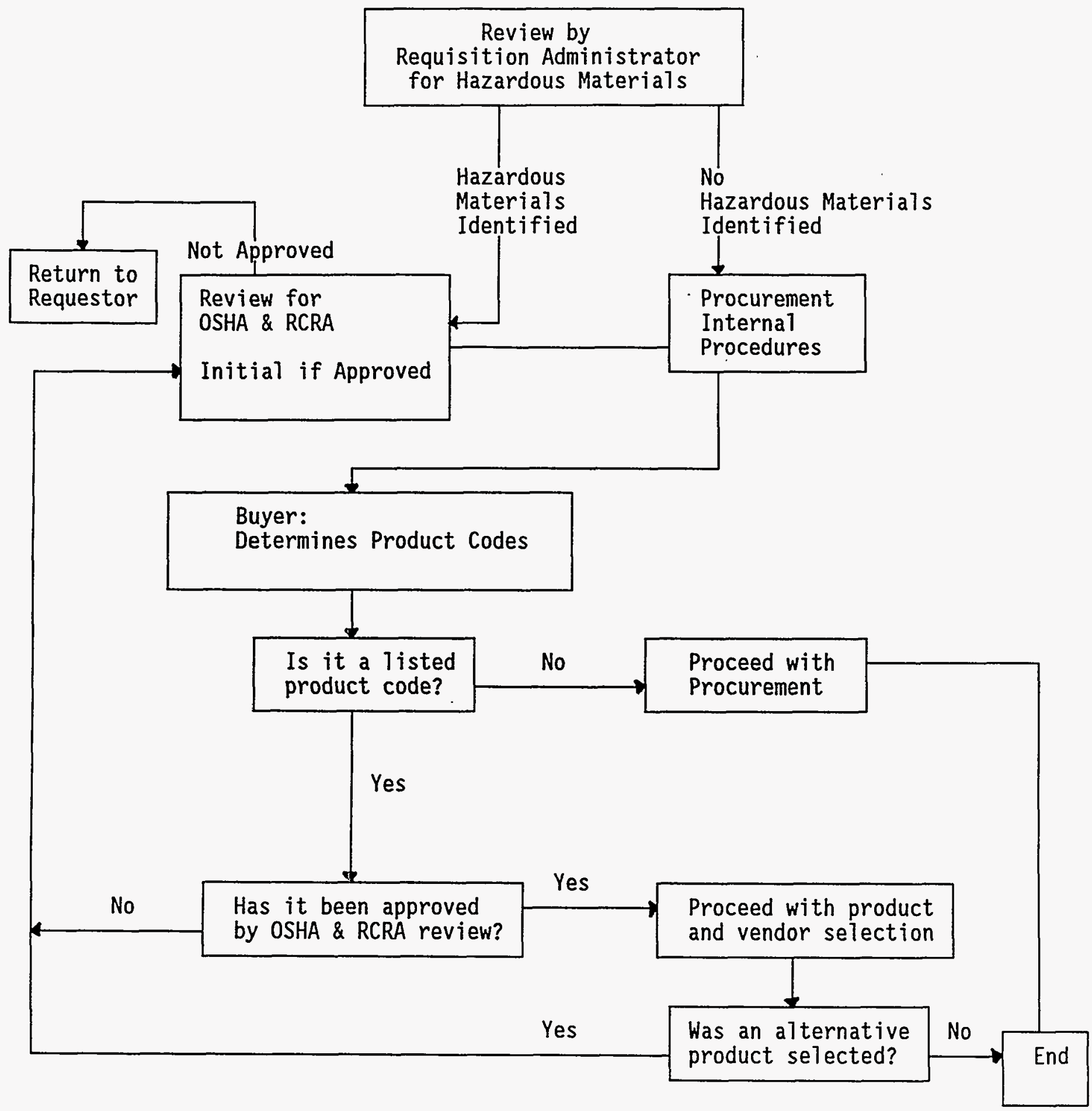

OSHA = Occupational Safety and Health Administration

RCRA $=$ Resource Conservation and Recovery Act of 1976 


\subsection{MODIFICATIONS}

The use of product codes, assigned by the buyer, to flag purchase requisitions would require additional effort by Procurement that may not be required to have an effective control program. This requirement was initially eliminated and will be evaluated later to determine if any significant loss to the program could be detected through alternative product selection by the buyer. Monthly checks of products identified for procurement versus products actually purchased showed that no equivalents had been substituted by the buyer during a 6-month review period. The proposed use of product codes to flag and track purchase requisitions was therefore dropped.

During the review of items being purchased in the early months of the initiative, the following things were noted:

- Some nonhazardous products requested were probably available from excess

- Case lot quantities were being requested when perhaps only one or two containers were actualty needed

- Some products might have been available from other facilities either because the facilities are known to use significant quantities or because the products have not yet been identified as excess

- Some products were being ordered often, either by the same facility or by several facilities, and might be handled better as a Stores Stock item

- Occasionally products were being ordered that were currently in Stores Stock.

Based on these observations, several changes were made during the first few months of the project: (1) nonhazardous products were included in the check for existing surplus, (2) requestors were asked to indicate on purchase requisitions that additional handling charges should be authorized where necessary to avoid purchasing case lot quantities when only a few containers were needed, (3) a check of the Stores catalog was made to determine if the item was already available, and (4) the HMID2 inventory database and recent purchase requisitions were included in the check for availability from other sources on site. 


\section{WHC-MR-0484}

This page intentionally left blank. 


\subsection{IMPLEMENTATION (WORKING MODEL)}

\subsection{TOOLS}

Several working tools had to be developed to have a successful HMRI program. Fortunately the tools are relatively easy, although time consuming, to develop and can be developed during the program implementation. The following tools. were developed for the HMRI program.

1. A listing of materials purchased that are not included in store stock. Information for each material should include a number (or other tracking system) for the applicable material safety data sheet, product name, quantity ordered, unit of issue (e.g., gallon, kilogram, ea.), name and location of requestor, and date ordered. It may be advantageous to create multiple listings by product categories (see Section 6.0).

2. An alternative product listing. This listing should include a detailed description of the product's application or end use, product name, manufacturer. potential waste codes, and a reference to a material safety data sheet. Key words such as PAINT, EXTERIOR, METAL may be usefuT but if separate listings are maintained by application type then a computer with word processing capabilities is adequate.

3. A product predetermination resource. Before obtaining samples and testing alternative products, a material safety data sheet should be obtained for each product and applicable waste codes determined for as-received product, empty containers, used product, and waste containing less than $10 \%$ product. This information is often useful in determining which products to test and if more than one product is a suitable alternative it helps determine which to choose. Since many products have more than one application, a listing of each product receiving a predetermination and the results of that predetermination should be maintained. This service is provided by the Site Services Organization at WHC. In addition to recording this information the Site Services Organization also includes product application, review date, and reference to the material safety data sheet. Since this can become a lengthy list a database would be advantageous; however, a word processor will provide adequate retrieval capabilities.

\subsection{CURRENT PROCEDURE}

Procurement receives all purchase requisitions at a central receiving location for review and entry into the procurement tracking system. Requisitions for hazardous or potentially hazardous materials, as defined by

${ }^{1}$ Although a database was used in the HMRI project development, the lack of transferability and training negated gains in productivity. A good word processing computer setup would be more than adequate for this process. 
OSHA, are set aside for the HMRI program. HMRI personnel review these requisitions to determine if they (1) are hazardous under Washington State or Resource Conservation and Recovery Act of 1976 (RCRA) regulations or (2) could possibly be filled from surplus stock. Copies are made of requisitions meeting either or both of these requirements and the originals returned to procurement for processing. The surplus materials list, provided by the Recycling Group, is checked to determine if similar material is available. If it is, the Recycling Group is contacted and a copy of the purchase requisition is provided to them for further action. If warranted, the Stores catalog is checked to determine if this is a stock item. In the event the material is a stocked item, the requestor is notified and asked to cancel the purchase requisition and issue a request for the material through Stores. The procurement coordinator is informed of the actions taken. Requested materials are entered into the appropriate HMRI listing for later use. The regulatory status of each item is verified either against current lists or following receipt of a material safety data sheet. If the regulatory status cannot be confirmed, a request for product predetermination is made to Site Services. In the latter case, no action is taken by HMRI. Prior requisitions and the HMID2 database are checked to determine if the materials identified as regulated might be available from onsite sources. If a match is found, the holder of the material is contacted to determine if they can fill all or part of the order from extra stock. Information needed to complete the transaction is then provided to both parties, and the requestor is asked to notify Procurement of any required changes to the purchase requisition. HMRI personnel do not inform Procurement of these actions. The product substitution listing is checked for potential alternatives that might fill the end-use requirements. Figure 2 shows the current purchase requisition flow and actions with the HMRI program in place. Figure 3 details how the Pollution Prevention Group, under HMRI, reviews purchase requisitions and proposes actions or alternatives. 
Figure 2. Final Purchase Requisition Flow IJsing the Hazardous Material Reduction Initiative.
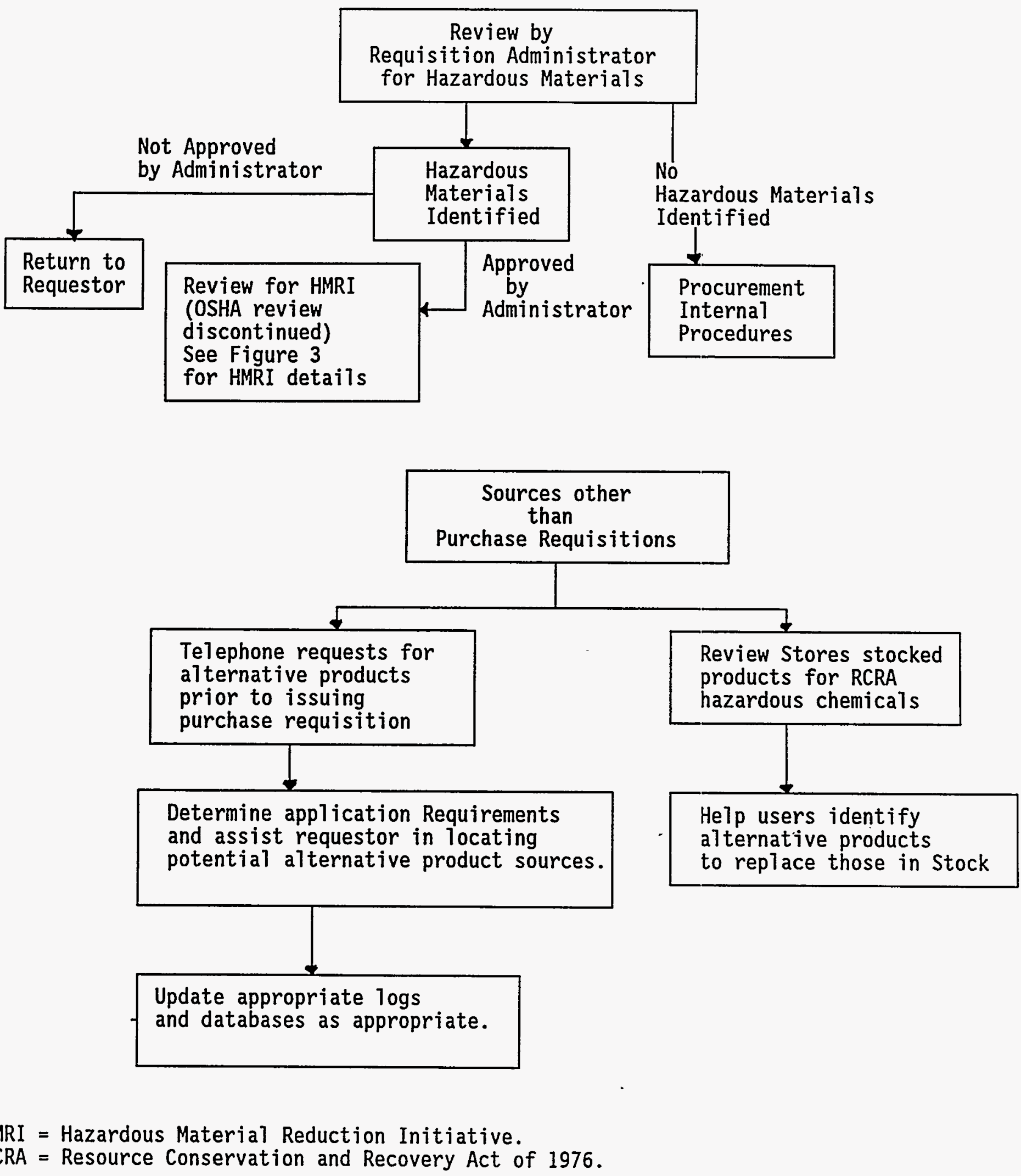
Figure 3. Hazardous Material Reduction Initiative Detail.

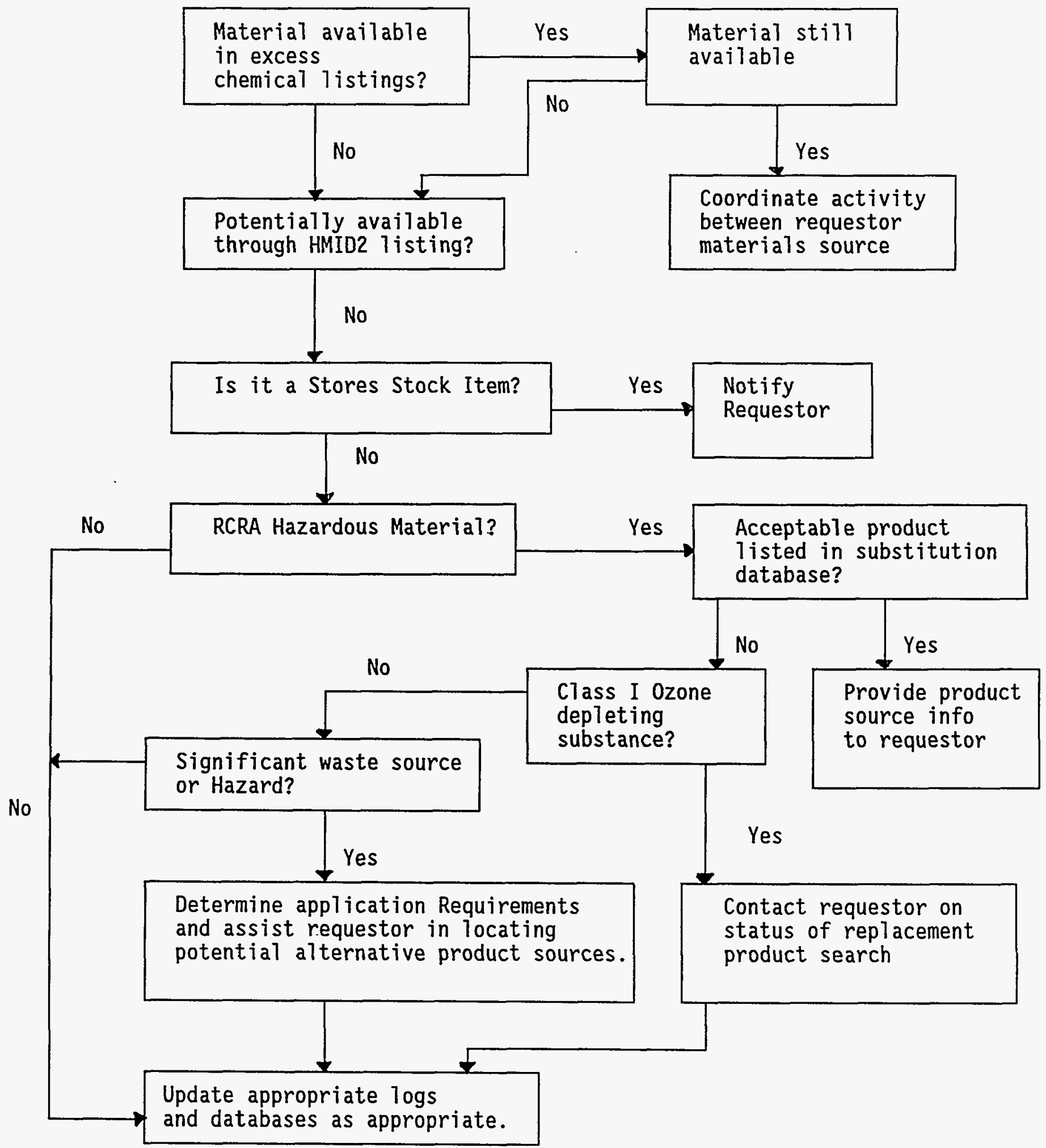

HMID2 = Hazardous material inventory database.

RCRA = Resource Conservation and Recovery Act of 1976. 


\subsection{PROBLEMS AND PLANNED IMPROVEMENTS}

\subsection{PROBLEMS}

An element of the recycling portion of the HMRI was a database to include a11 products classed as hazardous under OSHA. This database would provide access to the location and quantities of all materials onsite and their hazardous components, thus making it possible to locate material onsite to potentially fill orders. Industrial Safety was adding this feature as part of the HMID2 database. This feature of the HMRI program has been eliminated.

Often hazardous materials are specified and preclude the use of a]ternatives. These restrictions may be imposed by equipment manufacturers requiring that specific products be used for maintenance and operation, design engineers imposing restrictions for new process equipment: or modifications to existing processes, or aesthetic reasons where protective coatings must match currently applied materials.

Industria] Safety withdrew support from the HMRI project before the end of fiscal year 1994. This has the short-term effect of el iminating the available file of material safety data sheets. However, the material safety data sheets should be available through the Hanford Site local area network during fiscal year 1995.

A relatively minor problem exists in that, although alternatives have been identified for several products and applications, there are no requirements to use them. This seems to be less of a problem when the end users are directly involved in selecting alternative products.

\subsection{PLANNED IMPROVEMENTS}

Hanford Environmental Health Foundation (HEHF) maintains both current and historical material safety data sheets for the Hanford Site. Copies of these are available from HEHF. During 1995, access to material safety data sheets will be available through the Hanford Site 10cal area network. Scanned images of the material safety data sheet can be sent via facsimile (fax) 24 hours a day to any fax machine for a hard copy or to a PC Fax card for viewing. This will afford timely identification of the hazardous chemicals in the product. 
WHC-MR-0484

This page intentionally left blank. 


\subsection{ACCOMPLISHMENTS}

There were three goals established at the outset of this project: (1) develop a product substitution 1 ist, (2) reduce hazardous material procurement by $25 \%$, and (3) provide a nonintrusive program. With the exception of hazardous material reduction, these goals were met.

A list of alternative products has been developed for use at the Hanford Site. This list includes paints for interior and exterior use on both metal and nonmetal surfaces, solvents and cleaners, batteries, adhesives, sealants and fills, oils and lubricants, and other miscellaneous categories. Since many of the products on this list carry registered trademarks, it is available on request from the WHC Pollution Prevention Group.

Recycled products include 10 metric tons of sand blasting grit, $70 \mathrm{~kg}$ of anhydrous ammonia, smal1 quantities of paint, and several cans of aerosol products. Table 1 shows cumulative activities since the HMRI was implemented. Although total reductions did not account for $25 \%$ of the hazardous materials purchased, the reductions were nonetheless significant in volume.

The HMRI project delays the purchase requisition by at most one hour. Usually the delay is much less and has little or no impact on the procurement process.

The HMRI project was started before a product substitution listing was developed. Therefore, many a7ternatives were identified by end users based on earlier purchase requests. Alternative products identified include a urethane floor sealer, paint for property marking, primer paint for metal surfaces to chromate-based primers, and numerous absorbent products for organic or inorganic liquids. 
Table 1. Cumulative Requisitions Disposition since HMRI Implementation.

\begin{tabular}{|l|c|c|c|c||}
\hline \multicolumn{1}{|c|}{ Category } & $\begin{array}{c}\text { Number of } \\
\text { requisitions }\end{array}$ & $\begin{array}{c}\text { Quantity } \\
\text { requested } \\
\text { (kg) }\end{array}$ & $\begin{array}{c}\text { Product } \\
\text { Substitution } \\
\text { (kg) }\end{array}$ & $\begin{array}{c}\text { Obtained } \\
\text { from } \\
\text { surplus } \\
\text { (kg) }\end{array}$ \\
\hline $\begin{array}{l}\text { Solvents, cleaners, } \\
\text { and degreasers }\end{array}$ & 63 & 1,300 & 135 & \\
\hline Batteries & 38 & 1,200 & & \\
\hline Adhesives & 46 & 1350 & & \\
\hline Sealants and fills & 57 & 163,000 & & \\
\hline Paints & 155 & 46,300 & & \\
\hline 0ils, lubricants & 40 & 8,750 & & 10,000 \\
\hline Laboratory & 75 & 1,400 & & \\
\hline Miscellaneous & 186 & 750,000 & 10,000 \\
\hline Store stock & 660 & 973,425 & 955 & 10 \\
\hline \hline Total & & & & \\
\hline
\end{tabular}




\subsection{CONCLUSIONS}

A procurement control program can be an effective means of reducing the quantities of hazardous products entering the work place or requiring costly disposal. The method of procurement control will depend greatly on the local organizational structure and the number of purchase requisitions that involve hazardous materials. A decentralized procurement system was considered at WHC and would have seriously impacted the success of the project had it been implemented. The HMRI procedure works well at WHC. Some modifications may be necessary to accommodate significant differences between this facility and another site. These differences may include size, procurement procedures, and availability of required resources. 
WHC-MR-0484

This page intentionaliy left blank. 


\section{DISTRIBUTION}

Number of copies

OFFSITE

2

U.S. Department of Energy-

Headquarters

G. McBrian EM-334

ONSITE

2

U.S. Department of Energy, Richland Operations office

E. B. Dagan

B2-22

11

Westinghouse Hanford Company
J. R. Kirkenda11
B2-22
D. S. Merry
D. H. Nichols (6)
B2-22
Central Files
B2-22
OSTI (2)
L8-04
L8-07 
WHC-MR-0484

This page intentionally left blank.

Distr-2 